\title{
The stability and change of etiological influences on depression, anxiety symptoms and their co-occurrence across adolescence and young adulthood
}

\author{
M. A. Waszczuk ${ }^{1}$, H. M. S. Zavos ${ }^{1}$, A. M. Gregory ${ }^{2}$ and T. C. Eley ${ }^{1 *}$ \\ ${ }^{1}$ King's College London, MRC Social, Genetic and Developmental Psychiatry Centre, Institute of Psychiatry, Psychology and Neuroscience, London, \\ UK \\ ${ }^{2}$ Department of Psychology, Goldsmiths, University of London, London, UK
}

\begin{abstract}
Background. Depression and anxiety persist within and across diagnostic boundaries. The manner in which common $v$. disorder-specific genetic and environmental influences operate across development to maintain internalizing disorders and their co-morbidity is unclear. This paper investigates the stability and change of etiological influences on depression, panic, generalized, separation and social anxiety symptoms, and their co-occurrence, across adolescence and young adulthood.
\end{abstract}

Method. A total of 2619 twins/siblings prospectively reported symptoms of depression and anxiety at mean ages 15, 17 and 20 years.

Results. Each symptom scale showed a similar pattern of moderate continuity across development, largely underpinned by genetic stability. New genetic influences contributing to change in the developmental course of the symptoms emerged at each time point. All symptom scales correlated moderately with one another over time. Genetic influences, both stable and time-specific, overlapped considerably between the scales. Non-shared environmental influences were largely time- and symptom-specific, but some contributed moderately to the stability of depression and anxiety symptom scales. These stable, longitudinal environmental influences were highly correlated between the symptoms.

Conclusions. The results highlight both stable and dynamic etiology of depression and anxiety symptom scales. They provide preliminary evidence that stable as well as newly emerging genes contribute to the co-morbidity between depression and anxiety across adolescence and young adulthood. Conversely, environmental influences are largely time-specific and contribute to change in symptoms over time. The results inform molecular genetics research and transdiagnostic treatment and prevention approaches.

Received 1 May 2015; Revised 29 July 2015; Accepted 3 August 2015; First published online 27 August 2015

Key words: Adolescence, anxiety, depression, development, generalized anxiety, genetics, panic, separation anxiety, social anxiety, twins, young adulthood.

\section{Introduction}

Depression and anxiety disorders commonly co-occur (Angold et al. 1999; Costello et al. 2003; Kessler et al. 2005b; Beesdo et al. 2009; Gregory et al. 2007) and share multiple risk factors (Axelson \& Birmaher, 2001), including substantial genetic overlap (Kendler et al. 1987; Thapar \& McGuffin, 1997; Eley \& Stevenson, 1999; Mosing et al. 2009; Zavos et al. 2012; Waszczuk et al. 2014). Both are chronic and show homotypic (within-disorder) and heterotypic (across-disorder) continuity over time (Merikangas, 1993; Pine et al. 2001;

* Address for correspondence: Professor T. C. Eley, MRC Social, Genetic and Developmental Psychiatry Centre, Institute of Psychiatry, Psychology and Neuroscience, King's College London, Box PO80, De Crespigny Park, London SE5 8AF, UK.

(Email: thalia.eley@kcl.ac.uk)
Costello et al. 2003; Goodwin et al. 2004; Rutter et al. 2006; Ferdinand et al. 2007; Gregory et al. 2007; Moffitt et al. 2007; Trzaskowski et al. 2011; Lahey et al. 2014). Homotypic continuity suggests a degree of specificity of the constructs, in line with DSM-5 categorization (APA, 2013), in that the construct shows a fairly stable presentation. Additionally, heterotypic continuity also indicates an overlap between them, as proposed by transdiagnostic theories (Insel et al. 2010; Wilamowska et al. 2010). Furthermore, there are developmental differences in the phenotypic and genetic relationship between depression and different anxiety disorders (Axelson \& Birmaher, 2001; Bergen et al. 2007; Moffitt et al. 2007; Goldberg, 2008; Hettema, 2008; Mennin et al. 2008; Beesdo et al. 2009, 2010; Waszczuk et al. 2014). For example, we recently found age differences in phenotypic and genetic overlap between depression and a range of anxiety symptoms, with the association

This is an Open Access article, distributed under the terms of the Creative Commons Attribution licence (http://creativecommons. org/licenses/by/3.0/), which permits unrestricted re-use, distribution, and reproduction in any medium, provided the original work is properly cited. 
between these symptoms increasing markedly from adolescence, indicating developmentally dynamic etiology of internalizing problems (Waszczuk et al. 2014). As a result, genetic and environmental influences are likely to vary in their contribution to the continuity of depression, different anxiety subtypes, and their longitudinal co-occurrence across time. Understanding how these risk and maintenance factors operate across development is crucial for informing successful prevention and intervention strategies. Thus, the current study investigated the continuity and change of genetic and environmental influences on homotypic and heterotypic continuity of depression and four anxiety symptom scales across adolescence and young adulthood.

\section{Homotypic continuity}

To date longitudinal twin studies have focused largely on the contribution of genetic and environmental influences to homotypic continuity of depression, anxiety, or composite internalizing symptoms. Some studies have found that stable genetic influences contribute substantially to homotypic continuity across the lifespan (O'Connor et al. 1998; Gillespie et al. 2004; Trzaskowski et al. 2011; Garcia et al. 2013; Waszczuk et al. 2013). Conversely, other studies, primarily those of children and adolescents, have found that alongside genetic stability, new genetic influences emerge that contribute to change in symptoms over time (Scourfield et al. 2003; Van Der Valk et al. 2003; Bartels et al. 2004; Haberstick et al. 2005; Lau \& Eley, 2006; Kendler et al. 2008a, b; Zavos et al. 2012; Nivard et al. 2015; Lewis \& Plomin, 2015). This is in line with evidence that childhood and adolescence are more genetically dynamic than adulthood (Nivard et al. 2015).

The role of shared environmental influences is also unclear. Evidence from child samples suggests that stable shared environmental influences contribute to the homotypic continuity of symptoms (Schmitz et al. 1995; Silberg et al. 2001; Scourfield et al. 2003; Van Der Valk et al. 2003; Bartels et al. 2004; Kendler et al. 2008a), as well as to heterotypic continuity between different anxiety traits across time (Trzaskowski et al. 2011). This has generally not been replicated in older twins, possibly because shared environmental influences play a diminishing role in adolescence and adulthood (Rapee et al. 2009). Finally, non-shared environmental influences tend to be time-specific and contribute to change rather than stability of internalizing symptoms over time (Scourfield et al. 2003; Van Der Valk et al. 2003; Bartels et al. 2004; Haberstick et al. 2005; Lau \& Eley, 2006; Zavos et al. 2012; Garcia et al. 2013; Lewis \& Plomin, 2015). However, some studies have found that non-shared environmental influences can contribute to the homotypic continuity of depression and anxiety symptoms (O'Connor et al. 1998; Kendler et al. 2008a, 2011; Nivard et al. 2015).

Despite remarkable heterogeneity of anxiety disorders, to our knowledge only two studies to date have investigated the etiology of homotypic continuity of different anxiety symptoms. The first study examined three types of phobia from childhood to adulthood, and found more stable shared environmental influences on animal than situational and blood/injury fears (Kendler et al. 2008a). The second study investigated genetic and environmental influences on panic, separation and generalized anxiety symptoms across middle childhood, and found genetic stability and largely time-specific environmental influences consistently in the three symptoms (Waszczuk et al. 2013). To address this gap in the literature, the first aim of the current study was to systematically explore and compare the genetic and environmental influences on the homotypic continuity of depression and four anxiety symptom scales - panic, generalized, separation and social anxiety. We focused specifically on adolescence and young adulthood, developmental periods characterized by increased prevalence of depression and some of the anxiety disorders (Costello et al. 2003), and a time of substantial maturation of emotional processing (Yurgelun-Todd, 2007; Blakemore, 2008; Kadosh et al. 2013). In line with certain previous studies in adolescents we hypothesized that: (i) stable genetic factors would substantially contribute to homotypic continuity of each symptom in this age group, (ii) there would be time-specific genetic and environmental influences that contribute to change in the course of each symptom. We also explored whether there would be differences in the etiology of homotypic continuity across time between the symptom scales.

\section{Heterotypic continuity}

To date only two studies have examined how dynamic changes in etiological influences contribute to the comorbidity of internalizing disorders over time. The first study found that common genetic influences on childhood overanxious disorder and phobias continue to adolescence, where they also predict variance in adolescent depression (Silberg et al. 2001). Furthermore, shared environmental influences contributed to heterotypic continuity between some of the internalizing symptoms. The second study found that the genetic influences on childhood separation anxiety disorder continue to influence adult onset panic attacks (Roberson-Nay et al. 2012). However, the degree to which stable and time-specific etiological influences are shared between depression and anxiety disorder symptoms across development remains largely unknown. Understanding how genetic and environmental influences contribute 
to the co-morbidity of internalizing symptoms over time might provide clinically-relevant insights in the context of growing interest in transdiagnostic interventions. Given a remarkably high genetic overlap and small to moderate non-shared environmental correlations between these multiple disorders (Kendler et al. 1987; Eley \& Stevenson, 1999; Thapar \& McGuffin, 1997; Spatola et al. 2007; Mosing et al. 2009; Zavos et al. 2012; Waszczuk et al. 2014), we tentatively hypothesized that: (iii) both stable and time-specific genetic influences would contribute to the longitudinal co-morbidity between depression and anxiety symptom scales, (iv) environmental influences would not contribute markedly to the longitudinal co-morbidity.

\section{Method}

\section{Participants}

The analyses use data from waves $2-4$ (hereafter referred to as times 1-3 respectively) of a longitudinal twin and sibling study, the Genesis 1219 (G1219). Full details are provided elsewhere (McAdams et al. 2013) (see Supplementary Method). The study was given ethical approval by the Research Ethics Committee of the Institute of Psychiatry, King's College, London, South London and Maudsley NHS Trust and Goldsmiths, University of London. Informed consent was obtained from parents of adolescents under 16 years and from participants over 16. The sample size at time 1 was 1372 pairs [350 monozygotic (MZ), 313 dizygotic same-sex (DZss), 334 dizygotic opposite-sex (DZos), 330 siblings; 56\% female; mean age 15 years (range 12-21, S.D. $=1.67$ )], at time 2 it was 866 pairs [234 MZ, 207 DZss, 232 DZos, 182 siblings; $60 \%$ female; mean age 17 years (range 14-23, S.D. $=1.67)]$, and at time 3 it was 896 pairs [230 MZ, 214 DZss, 232 DZos, 201 siblings; 61\% female; mean age 20 years (range 18-27, s.D.=1.76)]. The inclusion of siblings inevitably resulted in large age ranges; however, $72 \%$ of the participants were twins with a tighter age range (e.g. at time 2, age S.D. $=1.11$, range $=15-19$ for twins, age s.D. $=1.97$, range $=15-23$ for siblings). Attrition was predicted by socioeconomic status (responses were more likely from individuals with parents reporting higher qualifications and home ownership), delinquency (individuals reporting lower levels of delinquent behavior were more likely to stay in the study) and sex (females were more likely than males to remain in the study), but not by zygosity and internalizing symptoms.

\section{Measures}

\section{Depression symptoms}

At each time the participants completed the Short Mood and Feelings Questionnaire (Angold et al. 1995), a 13-item self-report measure assessing how often depression symptoms occurred in the past 2 weeks. Responses were summed to give total depression scores. The measure demonstrates good reliability and validity (Angold et al. 1995) and the internal consistency was very high in the current study $(\alpha=0.79-0.90)$.

\section{Anxiety symptoms}

The adolescents (times 1 and 2) completed the Spence Children's Anxiety Scale (Spence, 1998); a 38-item self-report questionnaire tapping common anxiety symptoms. Adults (time 3) completed the Revised Symptoms of Anxiety Scale (see Gregory et al. 2011), an age-appropriate version of the Revised Child Anxiety and Depression Scale (Chorpita et al. 2000), consisting of 36 self-report items designed to assess DSM-IV anxiety disorder symptoms. Responses were summed to create four DSM-IV-related anxiety symptom scales: panic, generalized, separation and social anxiety. Subscales were originally derived using exploratory factor analyses conducted in large, independent samples (Spence, 1997, 1998; Chorpita et al. 2000). All measures have good internal consistency ( $\alpha=0.66-0.77$ for separation anxiety, $\alpha=0.70-0.90$ for all other scales) (Spence, 1998; Birmaher et al. 1999; Chorpita et al. 2000; Gregory et al. 2011).

The internal consistencies and descriptive statistics of all measures were comparable to published samples and are presented elsewhere (Waszczuk et al. 2014).

\section{Analyses}

The twin design compares the similarity between MZ (sharing $100 \%$ of their genes) and DZ (sharing on average $50 \%$ of their segregating genes) twin pairs. Differences in within-pair correlations allows estimations of the influences of additive genetics (A), shared environment $(\mathrm{C})$ factors that contribute to phenotypic similarity between siblings) and non-shared environment ( $\mathrm{E}$, factors that contribute to phenotypic differences between siblings). Quantitative genetic methods are described comprehensively elsewhere (Rijsdijk \& Sham, 2002; Plomin et al. 2013).

Models were fitted using OpenMx (Boker et al. 2011) within R [http://www.R-project.org (Team RDC, 2010)], a structural equation modeling package for genetically informative data. As is standard in model fitting analysis, variables were regressed for age and sex (McGue \& Bouchard, 1984), and any with skew >1 were transformed.

Models were fitted using raw data maximum likelihood. The core fit statistic was minus twice the log likelihood (-2LL) of the observations. This is not an overall measure of fit, but provides a relative measure of fit, since differences in -2LL between models are 
distributed as $\chi^{2}$. To examine the overall fit of the genetic model we compared the -2LL to that of a saturated model (which fully describes data using the maximum number of free parameters, estimating variances, covariances and means for the raw data to get a baseline index of fit). The fit of sub-models was assessed by $\chi^{2}$ difference tests, i.e. Akaike's Information Criterion (AIC) and Bayesian Information Criterion, with lower values suggesting a better fit. If the difference between AIC of two models was $<10$, the more parsimonious model was selected (Wagenmakers \& Farrell, 2004). Information about the precision of parameter estimates was obtained by likelihood-based confidence intervals.

Univariate genetic analyses were conducted on all variables at each time. Males and females showed differences in variance on all variables except for social anxiety, and a scalar was fitted to account for this difference (Waszczuk et al. 2014). Quantitative sex differences were tested to see whether males and females differ in magnitude of genetic and environmental influences, but such differences were not found. Finally, comparisons indicated that covariances, means and variances could be equated across DZ twins and siblings for all variables.

\section{Homotypic continuity}

Multivariate models best suited to investigate specific research questions were chosen a priori. The Cholesky decomposition (Fig. 1a) was used to examine the homotypic continuity of etiological influences separately for each variable. The Cholesky decomposition assumes three distinct sets of genetic and environmental influences on a variable at each time point. A1 and E1 are common factors on the first variable (paths $\mathrm{a}_{1}$ and $\mathrm{e} 1_{1}$ ) that can also influence the remaining two variables (paths $\mathrm{a}_{2-3}$ and $\mathrm{e} 1_{2-3}$, reflecting continuity from time 1 to times 2 and 3). A2 and E2 influence the second variable (paths $\mathrm{a} 22_{2}$ and $\mathrm{e} 22_{2}$, reflecting new genes emerging at time 2) and can also influence the third variable over and above the influences accounted for by A1 and $\mathrm{E} 1$ (paths $\mathrm{a} 2_{3}$ and $\mathrm{e} 2_{3}$, reflecting continuity from time 2 to time 3). A3 and E3 are unique influences specific to the third variable only (paths $a 3_{3}$ and $\mathrm{e} 3_{3}$, reflecting new influences emerging at time 3 ). Total $\mathrm{A}$ and $\mathrm{E}$ effects on each individual measure can be obtained by summing all squared paths to that measure (e.g. the proportion of total variance in third variable explained by $\mathrm{A}$ influences is obtained by summing squared paths $\mathrm{a} 1_{3}, \mathrm{a} 2_{3}$ and $\mathrm{a} 3_{3}$ ).

\section{Heterotypic continuity}

The common pathway model (Fig. 1b) was fitted in order to investigate the stability and change of the etiological influences shared between depression and anxiety symptom scales across development, to inform the mechanisms underpinning heterotypic continuity across time. The model is illustrated on Fig. $1 b$ (with just three variables for clarity); the model was run with all five variables included, each measured at three time points. This model assumes five latent factors; each underlying a variable assessed three times. For example, the depression latent factor captures the stability of the depression symptoms across times $1-3$. Variance of each latent factor is then decomposed into genetic $\left(\mathrm{A}_{1}\right)$ and environmental $\left(\mathrm{E}_{\mathrm{l}}\right)$ influences to assess the etiological factors underpinning the stability of each symptom. Of note, $E_{1}$ is free from time-specific measurement error but not from shared measurement error. The genetic and environmental correlations between the latent factors $\left(r_{\mathrm{Al}}\right.$ and $\left.r_{\mathrm{El}}\right)$ represent the degree of developmental stability common to depression and anxiety symptom scales. Any remaining variance (not explained by the latent factor) is then calculated as variable-specific genetic and environmental influences $\left(A_{s}\right.$ and $\left.E_{s}\right)$. The variable-specific etiological influences include genetic and environmental influences that emerge at later time points, and are allowed to correlate with the within-time influences on all other variables $\left(r_{\mathrm{As}}\right.$ and $\left.r_{\mathrm{Es}}\right)$, capturing timespecific associations between them.

\section{Results}

\section{Phenotypic correlations}

The longitudinal correlations between the variables across the three time points are presented in Table 1. All variables showed moderate homotypic continuity $(r=0.35-0.58)$. The heterotypic correlations between the different anxiety symptom scales, and between depression and each of the anxiety scales, were similar in magnitude and generally moderate $(r=0.12-0.46$ and $r=0.11-0.39$, respectively). Homotypic correlations were generally larger than heterotypic correlations, but tended to decrease at longer time intervals (times 1-3).

\section{Homotypic continuity}

The Cholesky decompositions show the effect of stable and new genetic and environmental factors across the three times, separately for each of the five symptom scales. The results were similar for depression and each anxiety symptom scale (Fig. 2). First, there was evidence of substantial genetic continuity, whereby genetic factors influencing symptoms at any one age continue to affect the symptom at subsequent ages. Second, the early influences gradually declined over time. For example, the first set of genetic factors (corresponding to path $1_{1}$ on Fig. $1 a$ ) accounted for $45 \%$ of the variance in generalized anxiety symptoms at age 
(a)

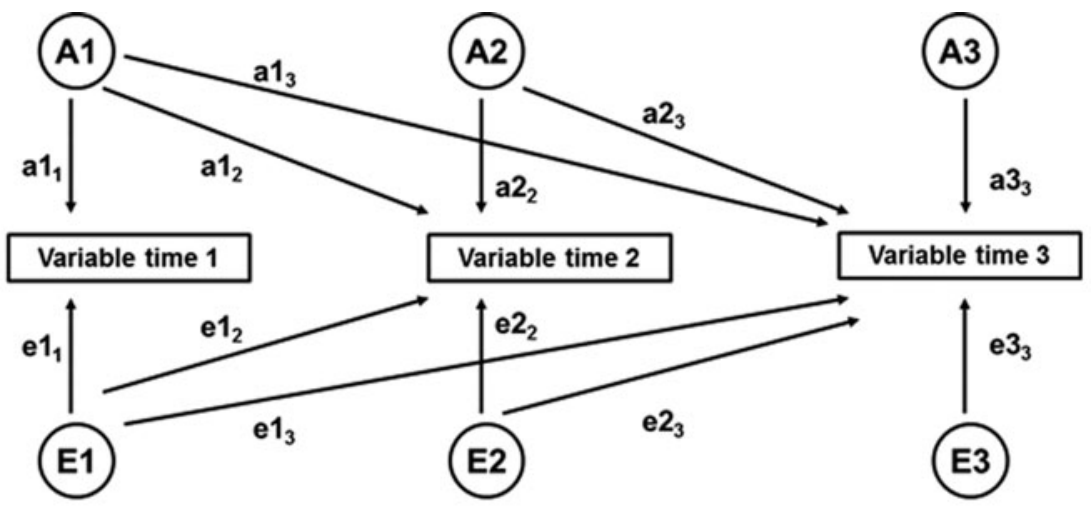

(b)
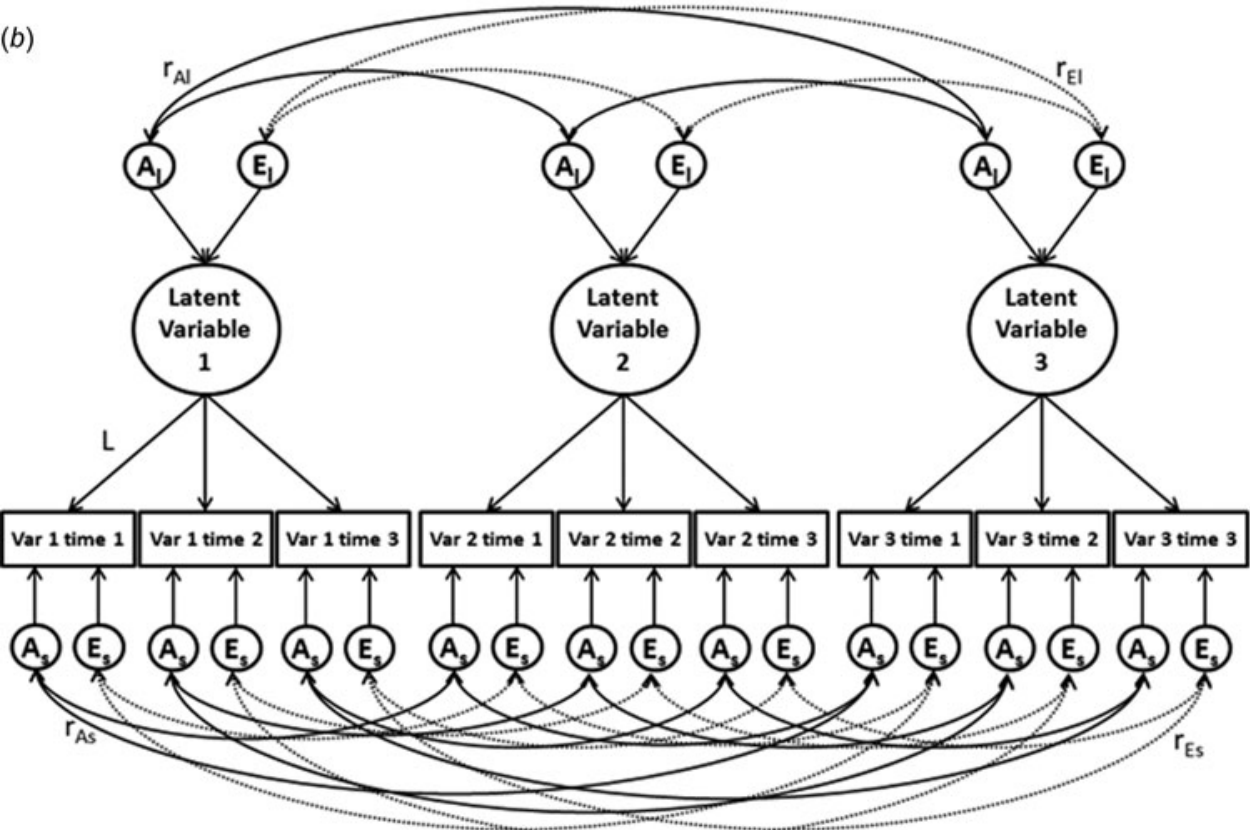

Fig. 1. Multivariate models: (a) longitudinal Cholesky decomposition, (b) Common pathway model. A, Additive genetic effects; E, non-shared environmental effects, Var, variable. Subscript ' 1 ' denotes stable influences on the latent factor, subscript ' $\mathrm{s}$ ' denotes variable- and time-specific influences. In panel $(a)$, variance paths, which must be squared to estimate the proportion of variance accounted for, are represented by lowercase letters and followed by two numerals, e.g. a1 $1_{1}, \mathrm{c} 2_{2}, \mathrm{e} 3_{3}$. In panel $(b)$, only three variables are presented for clarity; however the model was run with all five variables included, each measured at three time points.

15 , but reduced to $21 \%$ by age 17 (path $\mathrm{a} 1_{2}$ ) and $18 \%$ by age 20 (path $\mathrm{a}_{3}$ ). Third, new genetic factors emerged at each age (paths $a 2_{2}$ and $a 3_{3}$ ). Genetic influences that emerged at age 17 continued to influence symptoms at age 20 (path $\mathrm{a}_{3}$ ) in generalized anxiety, panic and social anxiety, but not in depression and separation anxiety. Separation anxiety was characterized by particularly high change in genetic influences over time.

Non-shared environmental influences on all symptoms were largely age-specific. For example, the nonshared environmental factors influencing generalized anxiety symptoms at age 15 had a small effect at age
17 , and no significant effect at age 20 . For $95 \%$ confidence intervals see Supplementary Table S1.

\section{Heterotypic continuity}

In the common pathway model the total variance in each variable is explained by the latent factor and the variable-specific influences. Stable influences accounted for $21-69 \%$ of the variance in each variable $\left(\mathrm{L}^{2}\right.$, see Table 2 note) and were largely influenced by genes $\left(A_{1}=0.61-0.76\right)$, with the remaining variance explained by modest to moderate, significant nonshared environmental influences $\left(\mathrm{E}_{1}=0.24-0.39\right)$ 
Table 1. Longitudinal phenotypic correlations

\begin{tabular}{|c|c|c|c|c|c|}
\hline & Depression & Panic & Generalized anxiety & Separation anxiety & Social anxiety \\
\hline Time 2 (17 years) & & & Time 1 (15 years) & & \\
\hline Depression & $0.47(0.43-0.51)$ & $0.33(0.29-0.37)$ & $0.31(0.27-0.35)$ & $0.24(0.19-0.29)$ & $0.30(0.26-0.34)$ \\
\hline Panic & $0.31(0.27-0.35)$ & $0.43(0.39-0.47)$ & $0.32(0.28-0.36)$ & $0.24(0.19-0.29)$ & $0.21(0.16-0.26)$ \\
\hline Generalized anxiety & $0.37(0.33-0.41)$ & $0.39(0.35-0.43)$ & $0.47(0.43-0.51)$ & $0.37(0.33-0.41)$ & $0.35(0.31-0.39)$ \\
\hline Separation anxiety & $0.11(0.06-0.16)$ & $0.22(0.17-0.27)$ & $0.22(0.17-0.27)$ & $0.36(0.32-0.40)$ & $0.16(0.11-0.21)$ \\
\hline Social anxiety & $0.29(0.24-0.33)$ & $0.29(0.24-0.33)$ & $0.34(0.30-0.38)$ & $0.31(0.27-0.35)$ & $0.53(0.49-0.56)$ \\
\hline Time 3 (20 years) & & & Time 1 (15 years) & & \\
\hline Depression & $0.38(0.34-0.42)$ & $0.32(0.28-0.36)$ & $0.26(0.21-0.31)$ & $0.24(0.19-0.29)$ & $0.24(0.19-0.29)$ \\
\hline Panic & $0.30(0.26-0.34)$ & $0.39(0.35-0.43)$ & $0.36(0.32-0.40)$ & $0.28(0.23-0.33)$ & $0.26(0.21-0.31)$ \\
\hline Generalized anxiety & $0.34(0.30-0.38)$ & $0.33(0.29-0.37)$ & $0.36(0.32-0.40)$ & $0.35(0.31-0.39)$ & $0.34(0.30-0.38)$ \\
\hline Separation anxiety & $0.32(0.28-0.36)$ & $0.40(0.36-0.44)$ & $0.35(0.31-0.39)$ & $0.39(0.35-0.43)$ & $0.32(0.28-0.36)$ \\
\hline Social anxiety & $0.33(0.29-0.37)$ & $0.33(0.29-0.37)$ & $0.38(0.34-0.42)$ & $0.31(0.27-0.35)$ & $0.46(0.42-0.50)$ \\
\hline Time 3 (20 years) & & & Time 2 (17 years) & & \\
\hline Depression & $0.47(0.43-0.51)$ & $0.34(0.30-0.38)$ & $0.38(0.34-0.42)$ & $0.12(0.07-0.18)$ & $0.31(0.27-0.35)$ \\
\hline Panic & $0.34(0.30-0.38)$ & $0.48(0.44-0.52)$ & $0.45(0.41-0.49)$ & $0.21(0.16-0.26)$ & $0.28(0.23-0.33)$ \\
\hline Generalized anxiety & $0.39(0.35-0.43)$ & $0.31(0.27-0.35)$ & $0.53(0.49-0.56)$ & $0.25(0.20-0.30)$ & $0.40(0.36-0.44)$ \\
\hline Separation anxiety & $0.35(0.31-0.39)$ & $0.40(0.36-0.44)$ & $0.46(0.42-0.50)$ & $0.35(0.31-0.39)$ & $0.36(0.32-0.40)$ \\
\hline Social anxiety & $0.39(0.35-0.43)$ & $0.30(0.26-0.34)$ & $0.46(0.42-0.50)$ & $0.17(0.12-0.22)$ & $0.58(0.54-0.62)$ \\
\hline
\end{tabular}

Mean ages provided in the headings.

Homotypic continuity is presented on diagonal (in bold), heterotypic continuity across diagonal.

95\% confidence intervals (CIs) are presented in parentheses. CIs not inclusive of zeros indicate significant correlations.

Non-overlapping CIs mean significant difference between the values.

Results presented on untransformed variables for comparison with other published samples. The within-time correlations between depression and anxiety subscales are discussed elsewhere (Lau et al. 2007; Waszczuk et al. 2014). The homotypic continuity of anxiety subscales has also previously been reported (Waszczuk et al. 2014).

(Table 2). The latent factors were generally highly correlated $\left(r_{\text {phl }}=0.58-0.83\right)$ (Table 3). Genetic influences on latent factors overlapped considerably $\left(r_{\mathrm{Al}}=0.60\right.$ $0.86)$ and the non-shared environmental correlations between the latent factors were also high $\left(r_{\mathrm{El}}=0.46-\right.$ 0.76 ) (Table 3). The variable-specific genetic influences were small $\left(\mathrm{A}_{\mathrm{s}}=0.01-0.26\right)$ (Table 2$)$, since most of the genetic influences acted via the latent factors. Conversely, variable-specific non-shared environmental influences were moderate $\left(E_{\mathrm{s}}=0.31-0.56\right)$ and accounted for most of the non-shared environmental influences on each variable (Table 2). The phenotypic within-time correlations between the variable-specific influences varied widely $\left(r_{\mathrm{phs}}=-0.12-0.56\right)$, as did the genetic and non-shared environmental within-time correlations between them (Table 3).

Model fit statistics for comparisons to the saturated models, and testing whether parameters can be dropped, are presented in Supplementary Table S2. Model fit statistics corroborate AE models and in the full models $\mathrm{C}$ estimates are very small. However, for completeness full ACE models are presented in Supplementary Tables S3-S5. Full ACE Cholesky decompositions suggest smaller genetic innovation than $\mathrm{AE}$ models (Supplementary Table S3). Otherwise dropping C from the models did not have impact on the interpretation of the results. The within-time analyses of these variables, including univariate ACE results, are presented elsewhere (Lau et al. 2007; Waszczuk et al. 2014). The longitudinal association between depression at times 1 and 2 was also reported previously (Lau \& Eley, 2006).

\section{Discussion}

The current study is the first to investigate how etiological influences contribute to developmental stability and change of depression, four anxiety symptom scales, and their co-occurrence across adolescence and young adulthood. The results provide support for largely stable and broad genetic influences accounting for co-occurrence and continuity over time. Environmental influences were generally more specific to time and symptom scales, contributing to change in symptoms over time.

\section{Homotypic continuity}

Genetic influences on symptoms stability

Moderate homotypic continuity of depression and each anxiety symptom scale across the 5 -year period was 


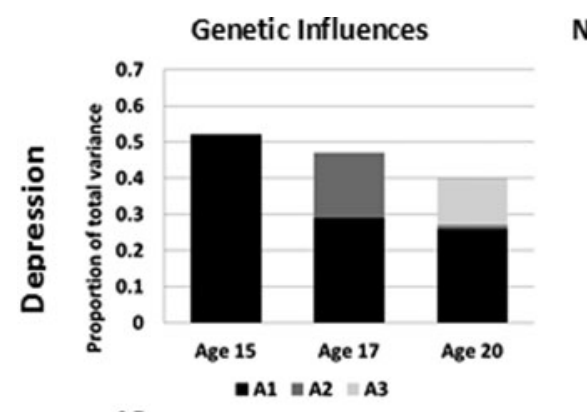

\section{Non-shared environmental Influences}
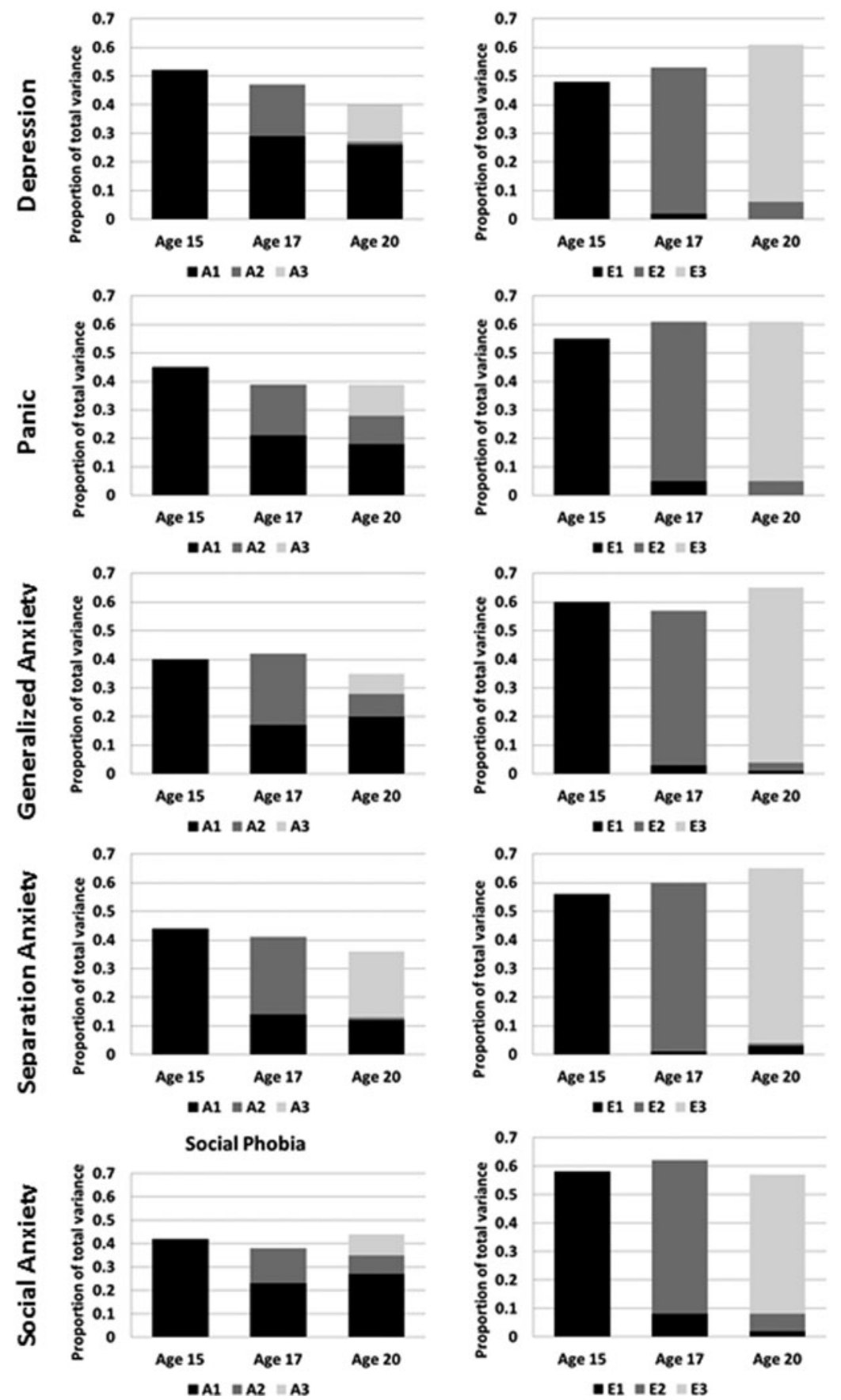

Fig. 2. Longitudinal Cholesky decomposition results: The proportion of total variance in depression and anxiety symptom scales accounted for by genetic and non-shared environmental influences. A, Additive genetic effects; E, non-shared environmental influences. Mean ages provided in the x-axis. The y-axis represents the total phenotypic variance so the sum of all the factors equals the total heritability/non-shared environmental influences. The first genetic/non-shared environmental factor (A1/E1), which influences a variable at mean age 15, is represented in black. A dark gray represents the second genetic/ non-shared environmental factor (A2/E2) that stars at mean age 17 years and the pale gray represents the third genetic/ non-shared environmental factor (A3/E3) that emerges at mean age 20 years. The $95 \%$ confidence intervals are presented in Supplementary Table S1. AE models are presented, as C influences were not significant and were dropped from the multivariate models without a significant deterioration of the fit (Supplementary Table S2). The AIC values suggest that dropping C leads to improvement of the model fit at these three waves. Full ACE results are presented in Supplementary Tables S3-S5 for completeness. 
Table 2. Common pathway model results: genetic and non-shared environmental influences on the latent factor, and latent factor and time-specific influences on each variable

\begin{tabular}{|c|c|c|c|c|c|c|c|c|c|c|c|c|c|c|c|c|}
\hline & & \multicolumn{3}{|l|}{ Depression } & \multicolumn{3}{|l|}{ Panic } & \multicolumn{3}{|c|}{ Generalized anxiety } & \multicolumn{3}{|c|}{ Separation anxiety } & \multicolumn{3}{|c|}{ Social anxiety } \\
\hline Etiological & $A_{1}$ & \multicolumn{2}{|c|}{$0.76(0.65-0.85)$} & & \multicolumn{2}{|c|}{$0.66(0.43-0.77)$} & & \multicolumn{2}{|c|}{$0.64(0.51-0.74)$} & & \multicolumn{2}{|c|}{$0.69(0.53-0.83)$} & & \multicolumn{2}{|c|}{$0.61(0.51-0.71)$} & \\
\hline $\begin{array}{l}\text { influences on } \\
\text { the latent } \\
\text { factor }\end{array}$ & $\mathrm{E}_{1}$ & \multicolumn{2}{|c|}{$0.24(0.15-0.35)$} & & \multicolumn{2}{|c|}{$0.34(0.23-0.46)$} & & \multicolumn{2}{|c|}{$0.36(0.26-0.49)$} & & \multicolumn{2}{|c|}{$0.31(0.17-0.47)$} & & \multicolumn{3}{|c|}{$0.39(0.29-0.49)$} \\
\hline $\begin{array}{l}\text { Mean age, } \\
\text { years }\end{array}$ & & 15 & 17 & 20 & 15 & 17 & 20 & 15 & 17 & 20 & 15 & 17 & 20 & 15 & 17 & 20 \\
\hline $\begin{array}{l}\text { Latent factor } \\
\text { influences on } \\
\text { each variable }\end{array}$ & L & $\begin{array}{l}0.63 \\
(0.58-0.67)\end{array}$ & $\begin{array}{l}0.78 \\
(0.73-0.83)\end{array}$ & $\begin{array}{l}0.58 \\
(0.52-0.62)\end{array}$ & $\begin{array}{l}0.56 \\
(0.51-0.61)\end{array}$ & $\begin{array}{l}0.71 \\
(0.66-0.76)\end{array}$ & $\begin{array}{l}0.61 \\
(0.56-0.66)\end{array}$ & $\begin{array}{l}0.57 \\
(0.52-0.61)\end{array}$ & $\begin{array}{l}0.83 \\
(0.78-86)\end{array}$ & $\begin{array}{l}0.58 \\
(0.53-0.63)\end{array}$ & $\begin{array}{l}0.55 \\
(0.50-0.61)\end{array}$ & $\begin{array}{l}0.46 \\
(0.38-0.52)\end{array}$ & $\begin{array}{l}0.60 \\
(0.54-0.66)\end{array}$ & $\begin{array}{l}0.61 \\
(0.57-0.65)\end{array}$ & $\begin{array}{l}0.82 \\
(0.78-0.86)\end{array}$ & $\begin{array}{l}0.68 \\
(0.63-0.72)\end{array}$ \\
\hline $\begin{array}{l}\text { Time-specific } \\
\text { etiological }\end{array}$ & $\mathrm{A}_{\mathrm{s}}$ & $\begin{array}{l}0.20 \\
(0.13-0.27)\end{array}$ & $\begin{array}{l}0.03 \\
(0.00-0.11)\end{array}$ & $\begin{array}{l}0.14 \\
(0.05-0.23)\end{array}$ & $\begin{array}{l}0.17 \\
(0.10-0.25)\end{array}$ & $\begin{array}{l}0.12 \\
(0.05-0.21)\end{array}$ & $\begin{array}{l}0.07 \\
(0.00-0.15)\end{array}$ & $\begin{array}{l}0.22 \\
(0.15-0.30)\end{array}$ & $\begin{array}{l}0.01 \\
(0.00-0.09)\end{array}$ & $\begin{array}{l}0.12 \\
(0.03-0.21)\end{array}$ & $\begin{array}{l}0.21 \\
(0.13-0.29)\end{array}$ & $\begin{array}{l}0.26 \\
(0.16-0.36)\end{array}$ & $\begin{array}{l}0.11 \\
(0.02-0.20)\end{array}$ & $\begin{array}{l}0.17 \\
(0.10-0.24)\end{array}$ & $\begin{array}{l}0.02 \\
(0.00-0.07)\end{array}$ & $\begin{array}{l}0.11 \\
(0.02-0.20)\end{array}$ \\
\hline $\begin{array}{l}\text { influences on } \\
\text { each variable }\end{array}$ & $\mathrm{E}_{\mathrm{s}}$ & $\begin{array}{l}0.41 \\
(0.35-0.47)\end{array}$ & $\begin{array}{l}0.36 \\
(0.28-0.43)\end{array}$ & $\begin{array}{l}0.53 \\
(0.45-0.63)\end{array}$ & $\begin{array}{l}0.51 \\
(0.44-0.58)\end{array}$ & $\begin{array}{l}0.37 \\
(0.28-0.46)\end{array}$ & $\begin{array}{l}0.56 \\
(0.47-0.65)\end{array}$ & $\begin{array}{l}0.45 \\
(0.38-0.53)\end{array}$ & $\begin{array}{l}0.31 \\
(0.22-0.38)\end{array}$ & $\begin{array}{l}0.54 \\
(0.46-0.63)\end{array}$ & $\begin{array}{l}0.48 \\
(0.41-0.56)\end{array}$ & $\begin{array}{l}0.53 \\
(0.44-0.64)\end{array}$ & $\begin{array}{l}0.53 \\
(0.44-0.62)\end{array}$ & $\begin{array}{l}0.45 \\
(0.39-0.53)\end{array}$ & $\begin{array}{l}0.31 \\
(0.24-0.37)\end{array}$ & $\begin{array}{l}0.44 \\
(0.36-0.52)\end{array}$ \\
\hline
\end{tabular}

A, Additive genetic effects; E, non-shared environmental effects; L, Latent factor.

Mean ages provided in the headings.

95\% confidence intervals (CIs) are presented in parentheses. CIs not inclusive of zeros indicate significant influences. Non-overlapping CIs mean significant difference between the values.

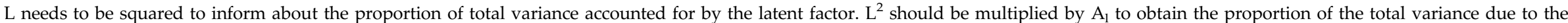

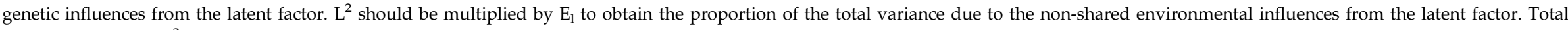
variance of a trait $=\mathrm{L}^{2}+\mathrm{A}_{\mathrm{s}}+\mathrm{E}_{\mathrm{s}}$.

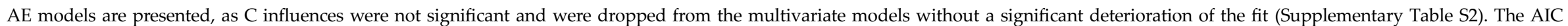
values suggest that dropping C lead to improvement of the model fit at these three waves. Full ACE results are presented in Supplementary Tables S3-S5 for completeness. 
Table 3. Common pathway model results: phenotypic, genetic and non-shared environmental correlations between the latent factors and time-specific influences at 15, 17 and 20 years

\begin{tabular}{|c|c|c|c|c|}
\hline & Depression & Panic & Generalized anxiety & Separation anxiety \\
\hline \multicolumn{5}{|c|}{ Latent factors } \\
\hline \multicolumn{5}{|c|}{ Panic } \\
\hline$r_{\mathrm{phl}}$ & $0.72(0.67$ to 0.76$)$ & & & \\
\hline$r_{\mathrm{Al}}$ & 0.74 (0.66 to 0.83$)$ & & & \\
\hline$r_{\mathrm{El}}$ & $0.67(0.46$ to 0.85$)$ & & & \\
\hline \multicolumn{5}{|c|}{ Generalized anxiety } \\
\hline$r_{\mathrm{phl}}$ & $0.74(0.69$ to 0.79$)$ & $0.83(0.79$ to 0.87$)$ & & \\
\hline$r_{\mathrm{Al}}$ & $0.81(0.73$ to 0.88$)$ & $0.86(0.79$ to 0.94$)$ & & \\
\hline$r_{\mathrm{El}}$ & $0.60(0.41$ to 0.76$)$ & $0.76(0.61$ to 0.89$)$ & & \\
\hline \multicolumn{5}{|c|}{ Separation anxiety } \\
\hline$r_{\mathrm{phl}}$ & $0.58(0.51$ to 0.65$)$ & $0.76(0.70$ to 0.82$)$ & $0.80(0.75$ to 0.85$)$ & \\
\hline$r_{\mathrm{Al}}$ & $0.60(0.48$ to 0.71$)$ & 0.78 (0.67 to 0.89$)$ & $0.86(0.76$ to 0.96$)$ & \\
\hline$r_{\mathrm{El}}$ & 0.55 (0.29 to 0.80$)$ & $0.73(0.51$ to 0.95$)$ & 0.70 (0.50 to 0.89$)$ & \\
\hline \multicolumn{5}{|c|}{ Social anxiety } \\
\hline$r_{\mathrm{phl}}$ & $0.63(0.58$ to 0.68$)$ & $0.62(0.56$ to 0.67$)$ & $0.75(0.71$ to 0.79$)$ & $0.65(0.59$ to 0.70$)$ \\
\hline$r_{\mathrm{Al}}$ & 0.67 (0.59 to 0.76$)$ & $0.68(0.57$ to 0.78$)$ & 0.77 (0.69 to 0.85$)$ & 0.75 (0.64 to 0.87$)$ \\
\hline$r_{\mathrm{El}}$ & $0.56(0.37$ to 0.72$)$ & $0.52(0.34$ to 0.67$)$ & $0.71(0.58$ to 0.83$)$ & $0.46(0.24$ to 0.65$)$ \\
\hline \multicolumn{5}{|c|}{ Time-specific influences at 15} \\
\hline \multicolumn{5}{|c|}{ Panic } \\
\hline$r_{\mathrm{phs}}$ & $0.43(0.38$ to 0.48$)$ & & & \\
\hline$r_{\text {As }}$ & $0.80(0.59$ to 0.99$)$ & & & \\
\hline$r_{\mathrm{Es}}$ & 0.28 (0.19 to 0.38$)$ & & & \\
\hline \multicolumn{5}{|c|}{ Generalized anxiety } \\
\hline$r_{\mathrm{phs}}$ & $0.44(0.39$ to 0.48$)$ & $0.49(0.44$ to 0.52$)$ & & \\
\hline$r_{\text {As }}$ & $0.57(0.37$ to 0.74$)$ & $0.56(0.32$ to 0.73$)$ & & \\
\hline$r_{\mathrm{Es}}$ & $0.38(0.28$ to 0.46$)$ & $0.46(0.38$ to 0.53$)$ & & \\
\hline \multicolumn{5}{|c|}{ Separation anxiety } \\
\hline$r_{\mathrm{phs}}$ & $0.34(0.29$ to 0.39$)$ & $0.40(0.36$ to 0.45$)$ & $0.43(0.38$ to 0.48$)$ & \\
\hline$r_{\text {As }}$ & $0.40(0.15$ to 0.59$)$ & $0.64(0.41$ to 0.86$)$ & $0.58(0.38$ to 0.76$)$ & \\
\hline$r_{\mathrm{Es}}$ & $0.31(0.22$ to 0.41$)$ & $0.31(0.22$ to 0.40$)$ & $0.36(0.27$ to 0.44$)$ & \\
\hline \multicolumn{5}{|c|}{ Social anxiety } \\
\hline$r_{\mathrm{phs}}$ & $0.36(0.31$ to 0.41$)$ & 0.37 (0.32 to 0.42$)$ & 0.48 (0.44 to 0.52$)$ & $0.46(0.42$ to 0.51$)$ \\
\hline$r_{\text {As }}$ & $0.61(0.38$ to 0.81$)$ & $0.64(0.39$ to 0.88$)$ & $0.81(0.62$ to 0.99$)$ & $0.66(0.44$ to 0.86$)$ \\
\hline$r_{\mathrm{Es}}$ & $0.26(0.16$ to 0.36$)$ & 0.28 (0.18 to 0.37$)$ & 0.35 (0.25 to 0.43$)$ & $0.39(0.29$ to 0.47$)$ \\
\hline \multicolumn{5}{|c|}{ Time-specific influences at 17} \\
\hline \multicolumn{5}{|c|}{ Panic } \\
\hline$r_{\mathrm{phs}}$ & 0.19 (0.09 to 0.28$)$ & & & \\
\hline$r_{\text {As }}$ & $0.41(-1.00$ to 1.00$)$ & & & \\
\hline$r_{\mathrm{Es}}$ & $0.15(0.00$ to 0.30$)$ & & & \\
\hline \multicolumn{5}{|c|}{ Generalized anxiety } \\
\hline$r_{\mathrm{phs}}$ & 0.27 (0.16 to 0.37$)$ & $0.38(0.29$ to 0.47$)$ & & \\
\hline$r_{\text {As }}$ & $-0.13(1.00$ to 1.00$)$ & $0.85(-1.00$ to 1.00$)$ & & \\
\hline$r_{\mathrm{Es}}$ & $0.29(0.13$ to 0.41$)$ & 0.38 (0.23 to 0.52$)$ & & \\
\hline \multicolumn{5}{|c|}{ Separation anxiety } \\
\hline$r_{\text {phs }}$ & $-0.12(-0.20$ to 0.04$)$ & $0.02(-0.06$ to 0.09$)$ & 0.11 (0.02 to 0.20$)$ & \\
\hline$r_{\text {As }}$ & $-0.33(-1.00$ to 1.00$)$ & $-0.16(-0.60$ to 0.20$)$ & $0.04(-1.00$ to 1.00$)$ & \\
\hline$r_{\mathrm{Es}}$ & $-0.08(-0.22$ to 0.05$)$ & $0.09(-0.06$ to 0.23$)$ & $0.13(-0.02$ to 0.27$)$ & \\
\hline \multicolumn{5}{|c|}{ Social anxiety } \\
\hline$r_{\mathrm{phs}}$ & 0.12 (0.01 to 0.22$)$ & $0.05(-0.06$ to 0.14$)$ & 0.16 (0.03 to 0.27$)$ & $0.03(-0.06$ to 0.11$)$ \\
\hline$r_{\text {As }}$ & $-0.45(-1.00$ to 1.00$)$ & $-0.94(-1.00$ to -0.12$)$ & $-0.76(-1.00$ to 1.00$)$ & $0.48(-0.27$ to 0.99$)$ \\
\hline$r_{\mathrm{Es}}$ & 0.17 (0.03 to 0.31$)$ & 0.20 (0.05 to 0.33$)$ & 0.20 (0.06 to 0.36$)$ & $-0.05(-0.19$ to 0.09$)$ \\
\hline \multicolumn{5}{|c|}{ Time-specific influences at 20} \\
\hline \multicolumn{5}{|c|}{ Panic } \\
\hline$r_{\mathrm{phs}}$ & $0.36(0.30$ to 0.42$)$ & & & \\
\hline
\end{tabular}


Table 3 (cont.)

\begin{tabular}{|c|c|c|c|c|}
\hline & Depression & Panic & Generalized anxiety & Separation anxiety \\
\hline$r_{\mathrm{As}}$ & $0.72(0.05$ to 1.00$)$ & & & \\
\hline$r_{\mathrm{Es}}$ & 0.30 (0.19 to 0.40$)$ & & & \\
\hline \multicolumn{5}{|c|}{ Generalized anxiety } \\
\hline$r_{\mathrm{phs}}$ & 0.42 (0.37 to 0.47$)$ & 0.44 (0.39 to 0.49$)$ & & \\
\hline$r_{\text {As }}$ & $0.45(-0.15$ to 0.79$)$ & $0.48(-0.07$ to 0.98$)$ & & \\
\hline$r_{\mathrm{Es}}$ & $0.42(0.31$ to 0.51$)$ & 0.44 (0.35 to 0.53$)$ & & \\
\hline \multicolumn{5}{|c|}{ Separation anxiety } \\
\hline$r_{\mathrm{phs}}$ & 0.38 (0.32 to 0.44$)$ & 0.44 (0.38 to 0.50$)$ & 0.47 (0.41 to 0.52$)$ & \\
\hline$r_{\text {As }}$ & $0.66(0.15$ to 0.98$)$ & $0.61(-0.58$ to 1.00$)$ & $0.63(-0.01$ to 0.95$)$ & \\
\hline$r_{\mathrm{Es}}$ & $0.32(0.21$ to 0.42$)$ & 0.42 (0.32 to 0.52$)$ & 0.43 (0.33 to 0.53$)$ & \\
\hline \multicolumn{5}{|c|}{ Social anxiety } \\
\hline$r_{\mathrm{phs}}$ & 0.45 (0.40 to 0.50$)$ & 0.47 (0.41 to 0.52$)$ & $0.56(0.51$ to 0.61$)$ & $0.43(0.37$ to 0.48$)$ \\
\hline$r_{\mathrm{As}}$ & 0.74 (0.31 to 0.99$)$ & $0.70(-0.25$ to 1.00$)$ & $0.69(0.13$ to 0.94$)$ & $0.33(-0.43$ to 0.79$)$ \\
\hline$r_{\mathrm{Es}}$ & $0.38(0.28$ to 0.48$)$ & 0.43 (0.34 to 0.53$)$ & 0.53 (0.45 to 0.62$)$ & 0.45 (0.34 to 0.55$)$ \\
\hline
\end{tabular}

$r_{\mathrm{phl}}$ Phenotypic correlations between the latent factors; $r_{\mathrm{Al}}$ genetic correlations between the latent factors; $r_{\mathrm{El},}$ non-shared environmental correlations between the latent factors; $r_{\mathrm{phs}}$, phenotypic correlations between the time-specific influences; $r_{\mathrm{As}}$, genetic correlations between the time-specific influences; $r_{\mathrm{Es}}$, non-shared environmental correlations between the time-specific influences.

95\% confidence intervals (CIs) are presented in parentheses. CIs not inclusive of zeros indicate significant correlations. Nonoverlapping CIs mean significant difference between the values.

AE models are presented, as $\mathrm{C}$ influences were not significant and were dropped from the multivariate models without a significant deterioration of the fit (Supplementary Table S2). The AIC values suggest that dropping C lead to improvement of the model fit at these three waves. Full ACE results are presented in Supplementary Tables S3-S5 for completeness.

observed, as expected (Costello et al. 2003; Rutter et al. 2006; Gregory et al. 2007). We found that stable genetic influences largely underpinned this continuity, in agreement with previous research that suggests strong genetic stability across development (O'Connor et al. 1998; Gillespie et al. 2004; Trzaskowski et al. 2011; Garcia et al. 2013; Waszczuk et al. 2013).

Environmental and genetic influences on symptoms change

The non-shared environmental influences on homotypic continuity of each symptom were largely time-specific, as expected (Scourfield et al. 2003; Van Der Valk et al. 2003; Bartels et al. 2004; Haberstick et al. 2005; Lau \& Eley, 2006; Zavos et al. 2012; Garcia et al. 2013; Lewis \& Plomin, 2015). Furthermore, we found new genetic influences emerged over time (genetic innovation; Kendler et al. 2008a) and previous genetic influences gradually declined over time (genetic attenuation), in agreement with other findings (Scourfield et al. 2003; Van Der Valk et al. 2003; Bartels et al. 2004; Haberstick et al. 2005; Lau \& Eley, 2006; Kendler et al. 2008a, b; Zavos et al. 2012; Nivard et al. 2015; Lewis \& Plomin, 2015). These newly emerging, developmentally dynamic environmental and genetic effects can contribute to change in the course of depression and anxiety symptoms.

The current study extends previous findings by investigating longitudinal etiological influences on homotypic continuity of depression and anxiety symptoms scales separately. A similar pattern of substantial genetic stability and largely time-specific environmental influences was observed on all symptoms, possibly due to a substantial overlap between the genes influencing depression and anxiety (Kendler et al. 1987; Thapar \& McGuffin, 1997; Eley \& Stevenson, 1999; Mosing et al. 2009; Zavos et al. 2012; Waszczuk et al. 2014). However, some differences were notable. Depression, generalized and social anxiety symptoms showed more genetic stability than panic and separation anxiety symptoms, where genetic influences tended to attenuate more sharply, with proportionately greater genetic innovation at age 17 (panic and separation anxiety symptoms) and 20 years (separation anxiety symptoms). This might reflect relatively late median age of onset of panic disorder (Costello et al. 2003; Kessler et al. 2005a), and that pediatric and adult-onset separation anxiety might differ considerably (Shear et al. 2006; Costello et al. 2011).

\section{Heterotypic continuity}

\section{Genetic influences on symptoms stability}

Heterotypic continuity across the symptom scales was significant, reflecting high co-morbidity between depression and anxiety symptoms (Merikangas, 1993; 
Pine et al. 2001; Costello et al. 2003; Goodwin et al. 2004; Rutter et al. 2006; Ferdinand et al. 2007; Gregory et al. 2007; Moffitt et al. 2007; Spatola et al. 2007; Trzaskowski et al. 2011). This longitudinal co-morbidity was largely explained by genetic overlap between the stable genetic influences that contribute to chronicity of each disorder, as well as overlap between the timespecific genetic influences. The time-specific influences represent developmentally dynamic genes that operate across short time periods and might reflect genes that come online in late adolescence or young adulthood. The current study provides preliminary evidence that both stable and time-specific genetic influences have general effects (i.e. on both depression and anxiety) (Eley, 1997), contributing to the enduring high genetic overlap between the symptom scales over time. These results carry implications for molecular genetic studies of depression and anxiety that aim to identify specific genetic variants involved in these disorders. They provide preliminary support for broadening the phenotypes included in molecular genetic studies, to increase power to detect shared susceptibility loci for a range of internalizing symptoms (O'Reilly et al. 2012; Hettema et al. 2015). However, the developmentally dynamic nature of genetic influences, in particular the genetic attenuation and innovation seen in adolescence suggests that stratifying sample collection by age may reduce heterogeneity (Zaitlen et al. 2012; Traylor et al. 2015). Identifying specific genes or polygenic risk scores may in turn inform clinical interventions, for example by using genetic markers to predict pharmacological or psychological treatment response (Keers \& Aitchison, 2011; Eley et al. 2012; Lester \& Eley, 2013).

\section{Environmental influences on symptoms change and stability}

As expected, environmental influences were largely timeand symptom-specific, thus contributing to the change in co-morbidity over time. However, a modest proportion of environmental influences contributed significantly to the stability of each symptom scale, albeit to a lesser extent than the genetic influences. The results are in line with some previous findings (O'Connor et al. 1998; Kendler et al. 2008a; Nivard et al. 2015), and extend them by showing that these stable non-shared environmental influences overlap considerably between depression and anxiety symptom scales, contributing to longitudinal co-morbidity. The results indicate that some environmental influences play a significant role in maintenance of depression and anxiety alongside genetic influences, possibly by producing enduring effects through biological and social changes in an individual (Kendler et al. 2011). These enduring environmental influences have an impact on a wide range of outcomes. These may include effects of severe environmental stressors such as childhood maltreatment or natural disasters (Kendler et al. 2000; Goenjian et al. 2005; Anda et al. 2006; Asselmann et al. 2015). Future studies should identify the life events that operate in this stable and broad manner to inform transdiagnostic interventions and prevention strategies (Barlow et al. 2004; Clark \& Taylor, 2009; McEvoy et al. 2009; Wilamowska et al. 2010; Weersing et al. 2012; Krueger \& Eaton, 2015).

\section{Limitations}

The genetically informative, representative sample and multiple time points are strengths of the current study. However, a number of limitations are noteworthy. First, our analyses used only self-report symptom scales and the results should be replicated in clinical samples with co-morbid diagnoses and using lifetime diagnostic interviews. This approach was taken because clinical levels of internalizing disorders are rare in general adolescent population and questionnaires might capture less severe symptoms of these disorders, for example self-reported panic might capture physical symptoms of anxiety rather than panic attacks. However, symptoms of internalizing disorders are important markers of psychopathology (Pickles et al. 2001; Fergusson et al. 2005; Balázs et al. 2013). Common mental disorders are now considered to be the extremes of quantitative traits (Plomin et al. 2009; Insel et al. 2010) and there is evidence that differently defined internalizing problems have the same etiology (Kendler et al. 1987; Kendler et al. 1992a, b). Second, at time 3 a different anxiety questionnaire was used reflecting the participants' older age. However, the longitudinal associations suggest a comparable continuity of the scores within and across different measures, in line with the view that they measure the same underlying constructs. Third, there was attrition in the sample. Although attrition bias might complicate estimation of trait prevalence, it is unlikely to affect the estimation of between trait associations (Wolke et al. 2009). Fourth, we did not measure other anxiety symptoms such as phobias, and future research should extend our findings to a wider range of internalizing symptoms. Fifth, future work should explore other types of continuity that were not addressed here, such as continuity across diagnoses. Last, there are limitations inherent to the twin design, discussed comprehensively elsewhere (Plomin et al. 2013). These have minimal and contrasting effects on parameter estimates which should be taken as indicative rather than absolute.

\section{Conclusions}

Our results suggest that both homotypic and heterotypic continuity of depression and anxiety symptoms across adolescence and young adulthood is underpinned largely by stable genetic influences, while 
non-shared environmental effects tend to be time- and symptom-specific. The results have multiple implications for future molecular genetics research and clinical practice in the context of co-morbidity. They affirm the need to continue examining how the risk and maintenance factors for internalizing psychopathology operate across development to inform successful prevention and intervention strategies.

\section{Supplementary material}

For supplementary material accompanying this paper visit http://dx.doi.org/10.1017/S0033291715001634.

\section{Acknowledgements}

The G1219 study was supported by a Medical Research Council Training Fellowship (G81/343) and a Career Development Award (G120/635) given to Thalia C. Eley. Waves 1-3 of G1219 were also funded by the W. T. Grant Foundation, the University of London Central Research fund and wave 4 was supported by the Economic and Social Research Council (RES-00022-2206), the Institute of Social Psychiatry (06/07-11), and a Leverhulme Research Fellowship (RF/2/RFG/ 2008/0145) awarded to Alice M. Gregory. Monika A. Waszczuk was supported by a PhD studentship funded by the Alexander von Humboldt Foundation. This work was also supported by the Leverhulme Foundation (RPG-210 to Thalia C. Eley). This study presents independent research partly funded by the National Institute for Health Research (NIHR) Biomedical Research Centre at South London and Maudsley NHS Foundation Trust and King's College London. The views expressed in this article are those of the authors and not necessarily those of the NHS, the NIHR, or the Department of Health. Monika A. Waszczuk had full access to all of the data in the study and takes responsibility for the integrity of the data and the accuracy of the data analysis. We thank the families for their participation as well as numerous staff and students from the Social Genetic Developmental Psychiatry Centre, Institute of Psychiatry, London and Goldsmiths, University of London.

\section{Declaration of Interest.}

None.

\section{References}

Anda RF, Felitti VJ, Bremner JD, Walker JD, Whitfield C, Perry BD, Dube SR, Giles WH (2006). The enduring effects of abuse and related adverse experiences in childhood. European Archives of Psychiatry and Clinical Neuroscience 256, 174-186.
Angold A, Costello EJ, Erkanli A (1999). Comorbidity. Journal of Child Psychology and Psychiatry 40, 57-87.

Angold A, Costello EJ, Messer SC, Pickles A, Winder F, Silver D (1995). The development of a short questionnaire for use in epidemiological studies of depression in children and adolescents. International Journal of Methods in Psychiatric Research 5, 1-12.

APA (2013). Diagnostic and Statistical Manual of Mental Disorders, DSM-5. American Psychiatric Publishing: Arlington, VA.

Asselmann E, Wittchen H-U, Lieb R, Höfler M, Beesdo-Baum K (2015). Danger and loss events and the incidence of anxiety and depressive disorders: a prospective-longitudinal community study of adolescents and young adults. Psychological Medicine 45, 153-163.

Axelson DA, Birmaher B (2001). Relation between anxiety and depressive disorders in childhood and adolescence. Depression and Anxiety 14, 67-78.

Balázs J, Miklósi M, Keresztény Á, Hoven CW, Carli V, Wasserman C, Apter A, Bobes J, Brunner R, Cosman D (2013). Adolescent subthreshold-depression and anxiety: psychopathology, functional impairment and increased suicide risk. Journal of Child Psychology and Psychiatry 54, 670-677.

Barlow DH, Allen LB, Choate ML (2004). Toward a unified treatment for emotional disorders. Behavior Therapy 35, 205-230.

Bartels M, Van Den Oord EJ, Hudziak JJ, Rietveld MJ, Van Beijsterveldt CE, Boomsma DI (2004). Genetic and environmental mechanisms underlying stability and change in problem behaviors at ages 3, 7, 10, and 12 . Developmental Psychology 40, 852-867.

Beesdo K, Knappe S, Pine DS (2009). Anxiety and anxiety disorders in children and adolescents: developmental issues and implications for DSM-V. Pediatric Clinics of North America 32, 483-524.

Beesdo K, Pine DS, Lieb R, Wittchen H (2010). Incidence and risk patterns of anxiety and depressive disorders and categorization of generalized anxiety disorder. Archives of General Psychiatry 67, 47-57.

Bergen SE, Gardner CO, Kendler KS (2007). Age-related changes in heritability of behavioral phenotypes over adolescence and young adulthood: a meta-analysis. Twin Research \& Human Genetics 10, 423-433.

Birmaher B, Brent DA, Chiappetta L, Bridge J, Monga S, Baugher M (1999). Psychometric properties of the Screen for Child Anxiety Related Emotional Disorders (SCARED): a replication study. Journal of the American Academy of Child $\mathcal{E}$ Adolescent Psychiatry 38, 1230-1236.

Blakemore S-J (2008). The social brain in adolescence. Nature Reviews Neuroscience 9, 267-277.

Boker S, Neale M, Maes H, Wilde M, Spiegel M, Brick T, Spies J, Estabrook R, Kenny S, Bates T (2011). OpenMx: an open source extended structural equation modeling framework. Psychometrika 76, 306-317.

Chorpita BF, Yim L, Moffitt C, Umemoto LA, Francis SE (2000). Assessment of symptoms of DSM-IV anxiety and depression in children: a revised child anxiety and depression scale. Behaviour Research and Therapy 38, 835-855. 
Clark DA, Taylor S (2009). The transdiagnostic perspective on cognitive-behavioral therapy for anxiety and depression: new wine for old wineskins? Journal of Cognitive Psychotherapy 23, 60-66.

Costello EJ, Copeland W, Angold A (2011). Trends in psychopathology across the adolescent years: what changes when children become adolescents, and when adolescents become adults? Journal of Child Psychology and Psychiatry 52, 1015-1025.

Costello EJ, Mustillo S, Erkanli A, Keeler G, Angold A (2003). Prevalence and development of psychiatric disorders in childhood and adolescence. Archives of General Psychiatry 60, 837-844.

Eley TC (1997). General genes: A new theme in developmental psychopathology. Current Directions in Psychological Science 6, 90-95.

Eley TC, Hudson JL, Creswell C, Tropeano M, Lester KJ, Cooper P, Farmer A, Lewis CM, Lyneham HJ, Rapee RM, Uher R, Zavos HMS, Collier DA (2012). Therapygenetics: the 5HTTLPR and response to psychological therapy. Molecular Psychiatry 17, 236-237.

Eley TC, Stevenson J (1999). Using genetic analyses to clarify the distinction between depressive and anxious symptoms in children and adolescents. Journal of Abnormal Child Psychology 27, 105-114.

Ferdinand RF, Dieleman G, Ormel J, Verhulst FC (2007). Homotypic versus heterotypic continuity of anxiety symptoms in young adolescents: evidence for distinctions between DSM-IV subtypes. Journal of Abnormal Child Psychology 35, 325-333.

Fergusson DM, Horwood LJ, Ridder EM, Beautrais AL (2005). Subthreshold depression in adolescence and mental health outcomes in adulthood. Archives of General Psychiatry 62, 66-72.

Garcia SE, Tully EC, Tarantino N, South S, Iacono WG, McGue M (2013). Changes in genetic and environmental influences on trait anxiety from middle adolescence to early adulthood. Journal of Affective Disorders 151, 46-53.

Gillespie NA, Kirk KM, Evans DM, Heath AC, Hickie IB, Martin NG (2004). Do the genetic or environmental determinants of anxiety and depression change with age? A longitudinal study of Australian twins. Twin Research 7, 39-53.

Goenjian AK, Walling D, Steinberg AM, Karayan I, Najarian LM, Pynoos R (2005). A prospective study of posttraumatic stress and depressive reactions among treated and untreated adolescents 5 years after a catastrophic disaster. American Journal of Psychiatry 162, 2302-2308.

Goldberg D (2008). Towards DSM-V: the relationship between generalized anxiety disorder and major depressive episode. Psychological Medicine 38, 1671-1675.

Goodwin RD, Fergusson DM, Horwood LJ (2004). Early anxious/withdrawn behaviours predict later internalising disorders. Journal of Child Psychology and Psychiatry and Allied Disciplines 45, 874-883.

Gregory AM, Buysse DJ, Willis TA, Rijsdijk FV, Maughan B, Rowe R, Cartwright S, Barclay NL, Eley TC (2011). Associations between sleep quality and anxiety and depression symptoms in a sample of young adult twins and siblings. Journal of Psychosomatic Research 71, 250-255.
Gregory AM, Caspi A, Moffitt TE, Koenen K, Eley TC, Poulton R (2007). Juvenile mental health histories of adults with anxiety disorders. American Journal of Psychiatry 164, 301-308.

Haberstick BC, Schmitz S, Young SE, Hewitt JK (2005). Contributions of genes and environments to stability and change in externalizing and internalizing problems during elementary and middle school. Behavior Genetics 35, 381-396.

Hettema J, Chen X, Sun C, Brown T (2015). Direct, indirect and pleiotropic effects of candidate genes on internalizing disorder psychopathology. Psychological Medicine 45, 2227-2236.

Hettema JM (2008). The nosologic relationship between generalized anxiety disorder and major depression. Depression and Anxiety 25, 300-316.

Insel T, Cuthbert B, Garvey M, Heinssen R, Pine DS, Quinn K, Sanislow C, Wang P (2010). Research domain criteria (RDoC): toward a new classification framework for research on mental disorders. American Journal of Psychiatry 167, 748-751.

Kadosh KC, Linden DE, Lau JY (2013). Plasticity during childhood and adolescence: innovative approaches to investigating neurocognitive development. Developmental Science 16, 574-583.

Keers R, Aitchison KJ (2011). Pharmacogenetics of antidepressant response. Expert Review of Neurotherapeutics 11, 101-125.

Kendler KS, Bulik CM, Silberg J, Hettema JM, Myers J, Prescott CA (2000). Childhood sexual abuse and adult psychiatric and substance use disorders in women: an epidemiological and cotwin control analysis. Archives of General Psychiatry 57, 953-959.

Kendler KS, Eaves LJ, Loken EK, Pedersen NL, Middeldorp CM, Reynolds C, Boomsma D, Lichtenstein P, Silberg J, Gardner CO (2011). The impact of environmental experiences on symptoms of anxiety and depression across the life span. Psychological Science 22, 1343-1352.

Kendler KS, Gardner CO, Annas P, Neale MC, Eaves LJ, Lichtenstein P (2008a). A longitudinal twin study of fears from middle childhood to early adulthood: evidence for a developmentally dynamic genome. Archives of General Psychiatry 65, 421-429.

Kendler KS, Gardner CO, Lichtenstein P (2008b). A developmental twin study of symptoms of anxiety and depression: evidence for genetic innovation and attenuation. Psychological Medicine 38, 1567-1575.

Kendler KS, Heath AC, Martin NG, Eaves LJ (1987). Symptoms of anxiety and symptoms of depression. Same genes, different environments? Archives of General Psychiatry 44, 451-457.

Kendler KS, Neale MC, Kessler RC, Heath AC, Eaves LJ (1992a). Major depression and generalized anxiety disorder. Same genes, (partly) different environments? Archives of General Psychiatry 49, 716-722.

Kendler KS, Neale MC, Kessler RC, Heath AC, Eaves LJ (1992b). A population-based twin study of major depression in women. The impact of varying definitions of illness. Archives of General Psychiatry 49, 257-266. 
Kessler RC, Berglund P, Demler O, Jin R, Merikangas KR, Walters EE (2005a). Lifetime prevalence and age-of-onset distributions of DSM-IV disorders in the National Comorbidity Survey Replication. Archives of General Psychiatry 62, 593-602.

Kessler RC, Chiu WT, Demler O, Merikangas KR, Walters EE (2005b). Prevalence, severity, and comorbidity of 12-month DSM-IV disorders in the National Comorbidity Survey Replication. Archives of General Psychiatry 62, 617-627.

Krueger RF, Eaton NR (2015). Transdiagnostic factors of mental disorders. World Psychiatry 14, 27-29.

Lahey BB, Zald DH, Hakes JK, Krueger RF, Rathouz PJ (2014). Patterns of heterotypic continuity associated with the cross-sectional correlational structure of prevalent mental disorders in adults. JAMA Psychiatry 71, 989-996.

Lau JYF, Eley TC (2006). Changes in genetic and environmental influences on depressive symptoms across adolescence and young adulthood. British Journal of Psychiatry 189, 422-427.

Lau JYF, Gregory AM, Goldwin MA, Pine DS, Eley TC (2007). Assessing gene-environment interactions on anxiety symptom subtypes across childhood and adolescence. Development and Psychopathology 19, 1129-1146.

Lester KJ, Eley TC (2013). Therapygenetics: using genetic markers to predict response to psychological treatment for mood and anxiety disorders. Biology of Mood \& Anxiety Disorders 3, 1-16.

Lewis GJ, Plomin R (2015). Heritable influences on behavioural problems from early childhood to mid-adolescence: evidence for genetic stability and innovation. Psychological Medicine 45, 2171-2179.

McAdams TA, Gregory AM, Rowe R, Zavos H, Barclay NL, Lau JY, Maughan B, Eley TC (2013). The genesis 12-19 (G1219) study: a twin and sibling study of geneenvironment interplay and adolescent development in the UK. Twin Research \& Human Genetics 16, 134-143.

McEvoy PM, Nathan P, Norton PJ (2009). Efficacy of transdiagnostic treatments: a review of published outcome studies and future research directions. Journal of Cognitive Psychotherapy 23, 20-33.

McGue M, Bouchard Jr. TJ (1984). Adjustment of twin data for the effects of age and sex. Behavior Genetics 14, 325-343.

Mennin DS, Heimberg RG, Fresco DM, Ritter MR (2008). Is generalized anxiety disorder an anxiety or mood disorder? Considering multiple factors as we ponder the fate of GAD. Depression and Anxiety 25, 289-299.

Merikangas KR (1993). Genetic epidemiologic studies of affective disorders in childhood and adolescence. European Archives of Psychiatry and Clinical Neuroscience 243, 121-130.

Moffitt TE, Harrington H, Caspi A, Kim-Cohen J, Goldberg D, Gregory AM, Poulton R (2007). Depression and generalized anxiety disorder: cumulative and sequential comorbidity in a birth cohort followed prospectively to age 32 years. Archives of General Psychiatry 64, 651-660.

Mosing MA, Gordon SD, Medland SE, Statham DJ, Nelson EC, Heath AC, Martin NG, Wray NR (2009). Genetic and environmental influences on the co-morbidity between depression, panic disorder, agoraphobia, and social phobia: a twin study. Depression and Anxiety 26, 1004-1011.
Nivard M, Dolan C, Kendler K, Kan K, Willemsen G, Van Beijsterveldt C, Lindauer R, Van Beek J, Geels L, Bartels M, Middeldorp CM, Boomsma DI (2015). Stability in symptom $\mathrm{s}$ of anxiety and depression as a function of genotype and environment: a longitudinal twin study from ages 3 to 63 years. Psychological Medicine 45, 1039-1049.

O'Connor TG, Neiderhiser JM, Reiss D, Hetherington EM, Plomin R (1998). Genetic contributions to continuity, change, and co-occurrence of antisocial and depressive symptoms in Adolescence. Journal of Child Psychology and Psychiatry 39, 323-336.

O'Reilly PF, Hoggart CJ, Pomyen Y, Calboli FC, Elliott P, Jarvelin M-R, Coin LJ (2012). MultiPhen: joint model of multiple phenotypes can increase discovery in GWAS. PLoS ONE 7, e34861.

Pickles A, Rowe R, Simonoff E, Foley D, Rutter M, Silberg J (2001). Child psychiatric symptoms and psychosocial impairment: relationship and prognostic significance. British Journal of Psychiatry 179, 230-235.

Pine DS, Cohen P, Brook J (2001). Adolescent fears as predictors of depression. Biological Psychiatry 50, 721-724.

Plomin R, Defries JC, Knopik VS, Neiderhiser JM (2013). Behavioral Genetics. Worth Publishers: New York.

Plomin R, Haworth CM, Davis OS (2009). Common disorders are quantitative traits. Nature Reviews Genetics 10, 872-878.

Rapee RM, Schniering CA, Hudson JL (2009). Anxiety disorders during childhood and adolescence: origins and treatment. Annual Review of Clinical Psychology 5, 311-341.

Rijsdijk FV, Sham PC (2002). Analytic approaches to twin data using structural equation models. Briefings in Bioinformatics 3, 119-133.

Roberson-Nay R, Eaves LJ, Hettema JM, Kendler KS, Silberg JL (2012). Childhood separation anxiety disorder and adult onset panic attacks share a common genetic diathesis. Depression and Anxiety 29, 320-327.

Rutter M, Kim-Cohen J, Maughan B (2006). Continuities and discontinuities in psychopathology between childhood and adult life. Journal of Child Psychology and Psychiatry 47, 276-295.

Schmitz S, Fulker DW, Mrazek D (1995). Problem behavior in early and middle childhood: an initial behavior genetic analysis. Journal of Child Psychology and Psychiatry 36, 1443-1458.

Scourfield J, Rice F, Thapar A, Harold GT, Martin N, McGuffin P (2003). Depressive symptoms in children and adolescents: changing aetiological influences with development. Journal of Child Psychology and Psychiatry and Allied Disciplines 44, 968-976.

Shear K, Jin R, Ruscio A, Walters E, Kessler R (2006). Prevalence and correlates of estimated DSM-IV child and adult separation anxiety disorder in the National Comorbidity Survey Replication. American Journal of Psychiatry 163, 1074-1083.

Silberg JL, Rutter M, Eaves L (2001). Genetic and environmental influences on the temporal association between earlier anxiety and later depression in girls. [Erratum appears in Biological Psychiatry 2001 50, 393.]. Biological Psychiatry 49, 1040-1049. 
Spatola CA, Fagnani C, Pesenti-Gritti P, Ogliari A, Stazi MA, Battaglia M (2007). A general population twin study of the CBCL/6-18 DSM-oriented scales. Journal of the American Academy of Child \& Adolescent Psychiatry 46, 619-627.

Spence SH (1997). Structure of anxiety symptoms among children: a confirmatory factor-analytic study. Journal of Abnormal Psychology 106, 280-297.

Spence SH (1998). A measure of anxiety symptoms among children. Behaviour Research \& Therapy 36, 545-566.

Teamrdc (2010). R: A Language and Environment for Statistical Computing. R Foundation for Statistical Computing: Vienna, Austria.

Thapar A, McGuffin P (1997). Anxiety and depressive symptoms in childhood - a genetic study of comorbidity. Journal of Child Psychology and Psychiatry 38, 651-656.

Traylor M, Markus H, Lewis CM (2015). Homogeneous case subgroups increase power in genetic association studies. European Journal of Human Genetics 23, 863-869.

Trzaskowski M, Zavos H, Haworth C, Plomin R, Eley T (2011). Stable genetic influence on anxiety-related behaviours across middle childhood. Journal of Abnormal Child Psychology 40, 85-94.

Van Der Valk JC, Van Den Oord EJ, Verhulst FC, Boomsma DI (2003). Genetic and environmental contributions to stability and change in children's internalizing and externalizing problems. Journal of the American Academy of Child \& Adolescent Psychiatry 42, 1212-1220.

Wagenmakers E-J, Farrell S (2004). AIC model selection using Akaike weights. Psychonomic Bulletin \& Review 11, 192-196.

Waszczuk MA, Zavos HMS, Eley TC (2013). Genetic and environmental influences on relationship between anxiety sensitivity and anxiety subscales in children. Journal of Anxiety Disorders 27, 475-484.

Waszczuk MA, Zavos HMS, Gregory AM, Eley TC (2014). The phenotypic and etiological structure of depression and anxiety disorder symptoms in childhood, adolescence and young adulthood. JAMA Psychiatry 71, 905-916.

Weersing VR, Rozenman MS, Maher-Bridge M, Campo JV (2012). Anxiety, depression, and somatic distress: developing a transdiagnostic internalizing toolbox for pediatric practice. Cognitive and Behavioral Practice 19, $68-82$.

Wilamowska ZA, Thompson-Hollands J, Fairholme CP, Ellard KK, Farchione TJ, Barlow DH (2010). Conceptual background, development, and preliminary data from the unified protocol for transdiagnostic treatment of emotional disorders. Depression and Anxiety 27, 882-890.

Wolke D, Waylen A, Samara M, Steer C, Goodman R, Ford T, Lamberts K (2009). Selective drop-out in longitudinal studies and non-biased prediction of behaviour disorders. British Journal of Psychiatry 195, 249-256.

Yurgelun-Todd D (2007). Emotional and cognitive changes during adolescence. Current Opinion in Neurobiology 17, 251-257.

Zaitlen N, Lindström S, Pasaniuc B, Cornelis M, Genovese G, Pollack S, Barton A, Bickeböller H, Bowden DW, Eyre $S$ (2012). Informed conditioning on clinical covariates increases power in case-control association studies. PLoS Genetics 8, e1003032.

Zavos HMS, Rijsdijk FV, Eley TC (2012). A longitudinal, genetically informative, study of associations between anxiety sensitivity, anxiety and depression. Behavior Genetics 42, 592-602. 